\title{
Intraperitoneal Adipose Tissue: Associated Health Risks, Quantification by Advanced Imaging Methods and Future Directions in Children
}

\author{
Madeleine Gantz ${ }^{1}$, Jun Chen ${ }^{1}$, Steven B. Heymsfield ${ }^{2}$ and Wei Shen ${ }^{*}, 1$ \\ ${ }^{I}$ Obesity Research Center, St. Luke's-Roosevelt Hospital and Institute of Human Nutrition, Columbia University, \\ College of Physicians and Surgeons, New York, USA \\ ${ }^{2}$ Merck and Co, Rahway, NJ, USA
}

\begin{abstract}
The prevalence of obesity continues to grow at an alarming rate and currently there are no highly effective long-term treatments for obesity at the population level. Targeting childhood is a critical component of the strategy for fighting the obesity epidemic and there is an important need to understand the relationship among adipose tissue distribution, growth and obesity-related health risks. Growing evidence supports the idea that visceral adipose tissue (VAT) is related to insulin resistance, metabolic syndrome, cardiovascular disease, diabetes and other medical conditions through blood drainage, hormonal factors, inflammation, and adipocytokines. Recent studies suggest that VAT is not a homogenous depot. Intraperitoneal and extraperitoneal adipose tissues (IPAT \& EPAT), the two subcomponents of VAT, have different venous blood drainage and may also differ in their associations with metabolic risk. The majority of previous studies have used imaging methods to measure the total amount of VAT. Few studies have established protocols for the analysis IPAT and EPAT and those that have are limited by their approximate nature and relatively large measurement error. To better understand the role of adipose tissue distribution in relation to the health consequences of obesity, accurate methods to separately measure IPAT and EPAT should be developed. Fortunately, children's characteristic VAT distribution permits easier differentiation between IPAT and EPAT than in adults. Future studies need to elaborate the role of regional VAT in growth and obesity with accurate quantification of IPAT and EPAT by advanced magnetic resonance imaging methods.
\end{abstract}

Keywords: Intraperitoneal adipose tissue, extraperitoneal adipose tissue, magnetic resonance imaging, growth, body composition.

\section{INTRODUCTION}

Obesity is becoming a global health risk and childhood obesity continues to increase at an alarming rate [1-4]. Visceral adipose tissue (VAT), though a small proportion of total adipose tissue, has been found to be closely related to health risks associated with obesity. Recent studies suggest that VAT is not a homogenous depot [5, 6]. Advanced imaging and surgery techniques have suggested that sub-depots of VAT, including intraperitoneal adipose tissue (IPAT) and extraperitoneal adipose tissue (EPAT), may have distinct metabolic activities [7-9]. IPAT, which consists of omental adipose tissue and mesenteric adipose tissue, is believed to be most strongly correlated with the health risks of obesity $[6,7,9,10]$.

Here we provide an overview of the relationship between health risks and IPAT based on a critical analysis of previously published results. We then examine existing imaging methods for measuring IPAT. Our report explores the importance of investigating IPAT in children and provides suggestions for future research. We believe that understanding the relationship between VAT and its growth in early childhood is an important component of the strategy for

*Address correspondence to this author at the Weight Control Unit, 1090 Amsterdam Ave, 14H, New York City, NY 10025, USA; Tel: 212-5231738; Fax: 212-523-3571; E-mail: WS2003@Columbia.edu preventing childhood obesity and fighting the obesity epidemic.

\section{IPAT AND RELATIONSHIP TO HEALTH RISKS}

VAT, particularly the IPAT portion located in the mesenteric and omental areas, has been shown to be associated with health risks in animal studies, cross-sectional human studies and longitudinal human studies. In particular, VAT is associated with metabolic syndrome, cardiovascular disease and type 2 diabetes, mainly through insulin resistance $[5,11$ 17]. Additionally, VAT increases the risk of developing gastroesophageal reflux [17-18], cholesterol gallstones [19, 20], sleep apnea [21, 22], Alzheimer's disease [23, 24], stroke [25], cancer [26], and other chronic medical conditions.

The first theory to relate VAT to health risks was the portal theory, which is based on the observation that VAT directly drains into the liver via the portal vein. The high lipolytic activity of VAT and the expansion of this adipose depot in obese subjects results in direct exposure of liver cells to high concentrations of free fatty acids [9, 27]. Fatty acids influence liver production of glucose and triglycerides and the clearance of insulin by the liver [27]; this may account for the high frequency of metabolic complications associated with abdominal obesity [7-9]. However, it is the intraperitoneal subdepot of VAT that drains into the portal vein, whereas EPAT empties into the inferior vena cava $[9$, 
10]. Thus, distinguishing IPAT from EPAT is important for understanding the role of regional adipose tissue distribution in obesity related health risks.

In recent years, it has been recognized that adipose tissue is an endocrine organ [28, 29]. Adipocytokines such as adiponectin, leptin and resistin may mediate insulin resistance or modulate the likelihood that obesity results in the development of type 2 diabetes [30]. Adiponectin has anti-inflammatory and anti-atherogenic effects as well as multiple beneficial effects on metabolism. As opposed to proinflammatory adipokines, adiponectin levels are reduced in obese or diabetic individuals, particularly among patients with excess visceral adiposity [31-33]. Reduction of adiponectin is independently related to type 2 diabetes [30, 34]. Similarly, the expression of adiponectin receptor AdipoR1 is reduced in adipose tissue of obese subjects, with lower expression in omental adipocytes than in subcutaneous adipocytes [35]. The down-regulation of adiponectin receptors in adipose tissue of obese subjects appears to be reversible and $80 \%$ of the expression can be restored after significant weight loss [35]. Although the action of adiponectin in the liver and in skeletal muscle cells has been studied, the role of adiponectin in adipocytes needs to be clarified in future studies [35]. Resistin, another adipocytokine, impairs insulin action on hepatic glucose production and inhibits glucose uptake in skeletal muscle [36-38]. Resistin is positively associated with VAT accumulation and may partially explain the relationship between adipose tissue distribution and cardiometabolic risk factors [39].

The relationship between VAT and health risks can also be partially attributed to its secretion of inflammatory markers such as tumor necrosis factor- $\alpha$ (TNF- $\alpha$ ) and interleukin-6 (IL-6) [32]. Additionally, obesity and VAT accumulation have been found to be the critical correlates of elevated plasma C-reactive protein (CRP) - another inflammatory marker - found in men with atherogenic dyslipidemia with the insulin resistance syndrome [40]. VAT also secretes markers of hemostasis and fibrinolysis [41, 42] and abdominal obesity is associated with increased plasma levels of fibrinogen, FVII and FVIII coagulant activities, as well as tissue plasminogen activator (TPA) antigen and its circulating inhibitor (PAI-1) [41, 43-45]. In addition, elevated serum vascular endothelial growth factor (VEGF), which is an important angiogenic factor implicated in normal and pathological vessel formation, is associated with VAT accumulation in human obese subjects [46].

In recent years, adipose tissue biopsies from human subjects undergoing surgery has made it possible to study the metabolic activity and its regulation in omental and mesenteric adipose tissue. Several adipokines are oversecreted by omental adipose tissue in obese subjects and it is believed that these adipokines may link obesity to cardiovascular or metabolic comorbidities [47]. Not only stromal-vascular cells such as macrophages and endothelial cells, but also adipocytes in adipose tissue are active in stimulating inflammation [47-49]. Hypertrophic adipocytes have recently been shown to shift their immune balance toward the production of proinflammatory molecules, causing dysregulated adipokine expression and secretion $[47,50,51]$. It has also been found that TNF- $\alpha$ expression is higher in omental adipose tissue than in subcutaneous adipose tissue (SAT), which could contribute to cardiovascular risk in centrally obese subjects [52]. In a study comparing omental adipose tissue, $\mathrm{SAT}$, and liver biopsies, twice as many macrophages were found in omental adipose tissue than in subcutaneous adipose tissue [53]. Omental adipose tissue macrophage infiltration was correlated with insulin sensitivity, triglycerides, aspartate aminotransferase (AST), and $\gamma$-glutamyl transpeptidase. These results suggest that macrophages in omental adipose tissue participate in cellular mechanisms favoring hepatic fibroinflammatory lesions in obese patients [53].

One recent study sampled omental, mesenteric and subcutaneous adipose tissue in diabetic subjects [6]. This study showed that mesenteric adipose tissue in obese diabetic subjects has a high rate of basal lipolysis and impaired isoproterenol stimulated lipolysis. The PPAR- $\gamma$ gene expressions in the mesenteric, but not omental or subcutaneous adipose tissue, were up regulated. The $11 \beta$ HSD1 and FAT/CD36 gene expressions were higher in mesenteric adipose tissue than in subcutaneous and omental adipose tissues. These findings suggest that the alterations of these genes in mesenteric adipose tissue may play a critical role in insulin resistance in type 2 diabetes and metabolic syndrome [6].

A few studies have investigated the health benefits of omental adipose tissue removal. Omentectomy combined with adjustable gastric banding in severely obese adults $\left(\right.$ BMI $>35 \mathrm{~kg} / \mathrm{m}^{2}$ ) improved oral glucose tolerance, insulin sensitivity, and fasting plasma glucose and insulin $2-3$ times more than adjustable gastric banding alone [27]. The omentectomy group tended to lose more weight than the control group who underwent adjustable gastric banding alone (mean $\pm \mathrm{SD}, 36 \pm 14 \mathrm{~kg} v s .27 \pm 17 \mathrm{~kg}, \mathrm{p}=0.07$ ). As the sample size in this study was relatively small, larger scale studies are needed to clarify whether the health benefits of omentectomy are independent of weight loss [27]. A surgical protocol titled 'digestive adaptation with intestinal reserve' (DAIR) consisting of omentectomy, vertical gastrectomy and reduction of the small intestine, improved neuroendocrine profile and resolved diabetes [54]. The removal of the ometum reduces a major component of IPAT, which is believed to contribute to the beneficial effects of DAIR including decreasing a source of IL- 6 , IL-8, TNF- $\alpha$, and resistin, as well as reducing insulin resistance in the liver [54]. However, the exact mechanism involved, other than weight loss, is not fully understood [55]. The lack of a control group in Santoro et al.'s study does not allow an accurate evaluation of the effects of omentectomy independent of vertical gastrectomy and reduction of the small intestine.

Surgical procedures have been used in animal studies in order to evaluate the effects of removing VAT on health risks. Omentectomy has been shown to increase insulin sensitivity in dogs [56]. Alternatively, rodent studies have shown that removal of EPAT can have beneficial health effects. It has been shown that removal of EPAT (i.e., perinephric and epididymal adipose tissue) prevents insulin resistance and glucose intolerance of aging in F344/Brown Norway and Zucker Diabetic Fatty rats [57], suggesting a potential causal relationship between VAT and insulin resistance. Similarly, Barzilai et al.'s study showed that removal of EPAT in moderately obese Sprague-Dawley rats 
improves hepatic insulin sensitivity [58]. While the original rationale for VAT's relation to health risks is based on the portal theory $[8,9]$, the adipose tissue depot removed in this study is not drained by the portal vein. Instead, the perinephric and epididymal adipose tissue are drained by the vena cava. Therefore, these animal studies suggest that there may be additional mechanisms involved in the detrimental effects of VAT other than portal drainage. There is evidence that a series of genes, which might be implicated in the insulin-stimulated glucose transporter 4 translocation, are differentially expressed in the epididymal adipose tissue of rats rendered obese by a high fat diet [59]. Barzilai et al.'s study reported that the removal of EPAT did not cause significant reduction of total fat amount or total weight compared to the control group $[57,58]$. Due to this fact, there is not enough evidence that the improvement of insulin sensitivity with removal of EPAT is mediated via weight loss. On the other hand, the findings in rodents may not necessarily be reproducible in humans. Future studies need to clarify the biological or pathological difference between IPAT and EPAT in humans as well as their role in obesity and associated health risks.

\section{IPAT MEASUREMENT}

Methods of direct measurement of VAT such as magnetic resonance imaging (MRI), computed tomography (CT), and ultrasound, have been applied to both animals and humans. MRI and CT enable the visualization and quantification of adipose tissue mass in different compartments [9]. The choice between the MRI and CT is usually based on cost and availability of scanners as well as accuracy and reliability of image analysis. CT generates relatively consistent tissue attenuation values among images, thus the quantification of adipose tissue for CT is easier to implement than that of MRI. To minimize radiation dose, CT has mostly been used as a single-slice method in studying abdominal AT Distribution. On the other hand, MRI has several advantages over CT including its lack of radiation exposure and superior imaging of soft tissue. Furthermore, the lack of radiation with MRI allows for the determination of the total volume of adipose tissue compartments, which requires a longer scanning time.

In a study that compared the MRI measurement of three human cadavers to the direct measurement of adipose tissue mass after dissection of the cadavers, MRI was found to be an accurate and precise technique for the evaluation of VAT mass as well as the assessment of IPAT and EPAT [9].

Despite the high accuracy in measuring regional adipose tissue, the application of whole body MRI is limited by cost in most studies. A single cross sectional slice at specific anatomic locations is often used as a compromise between cost and accuracy for measuring VAT [33, 60, 61]. In adults of a wide range of adiposity, it has previously been shown that total VAT volume can be accurately estimated using the single slice method (i.e., at the L3 vertebra or $5-10 \mathrm{~cm}$ above the L4-L5) [33, 61, 62]. Because large scale studies have not been used to determine the anatomic distribution of IPAT and EPAT in humans, it is unclear whether a single slice can accurately estimate IPAT or EPAT. Furthermore, the anatomic location at which a single slice can provide the best estimate of IPAT and EPAT total volumes is also unknown. Therefore, contiguous or multi-slice cross-sectional imaging methods, rather than single slice imaging methods, are the best choice when studying IPAT and EPAT, especially at the initial research stage.

In terms of distinguishing IPAT from EPAT on MRI slices, different methodologies exist for the approximate differentiation [9, 63-71]. Many studies rely on anatomic locations in order to establish an arbitrary line that separates the two compartments. For example, in previous studies, a straight line was drawn across the anterior border of the vertebra and the psoas major muscle, then continued tangentially toward the inferior borders of the ascending and descending colons and extended to the abdominal wall [63, $65,66]$. In slices where the kidneys were visible, an oblique line was drawn from the anterior border of the aorta and inferior vena cava to the anterior border of the kidney extending to the abdominal wall [63, 65-66]. IPAT was defined as the adipose tissue located anterior to the line drawn [63, 65-66]. However, it has been shown that this arbitrary method of quantifying IPAT and EPAT has an error of 3.8 to $49.4 \%$ when validated by high resolution MRI with the peritoneum visible [72] (Fig. 1).

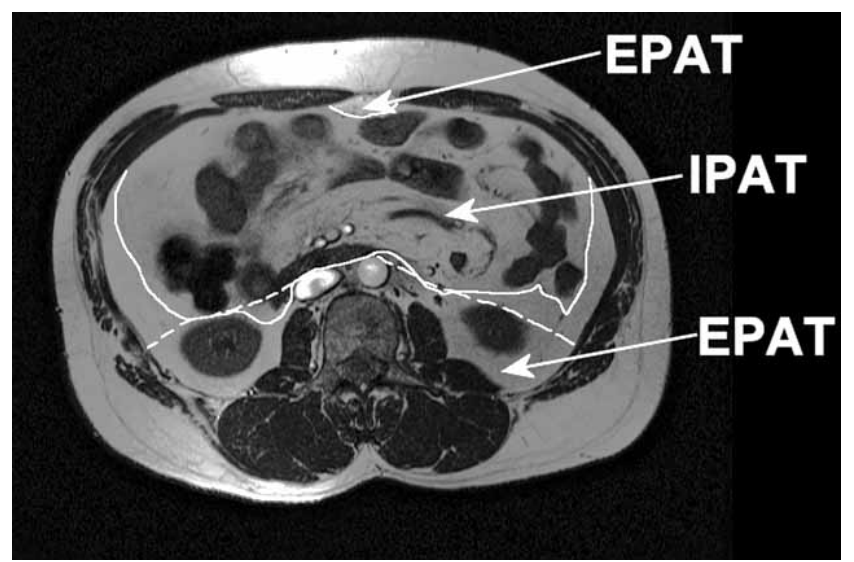

Fig. (1). The dashed line represents approximate separation of intraperitoneal adipose tissue (IPAT) and extraperitoneal adipose tissue (EPAT) as previously reported and the solid line represents visible separation of IPAT and EPAT [72].

The major difficulty for the separation of IPAT and EPAT in adults is that when VAT reaches a certain amount, IPAT and EPAT are adjacent to each other and common MRI protocols do not provide sufficient resolution for visualizing the fascia that separates the two compartments. The inconsistent reports on the relationship between IPAT and health risks in studies that use approximation methods could be attributed, at least partially, to the inaccurate measurement of the IPAT compartment. Although VAT can be detected in humans as early as infancy [73], there is a lack of studies on sub-dividing VAT into IPAT and EPAT in children. However, children have a much smaller VAT depot than adults [74] and omental adipose tissue is limited to the upper abdomen since the omentum is less developed in young children [75]. Therefore, the separation of IPAT and EPAT in children is more likely to be delineated by organs, even in children with a relatively large amount of VAT (Fig. 2). The Visible Human Project of the National Library of Medicine includes $1 \mathrm{~mm}$ thick consecutive high-resolution 


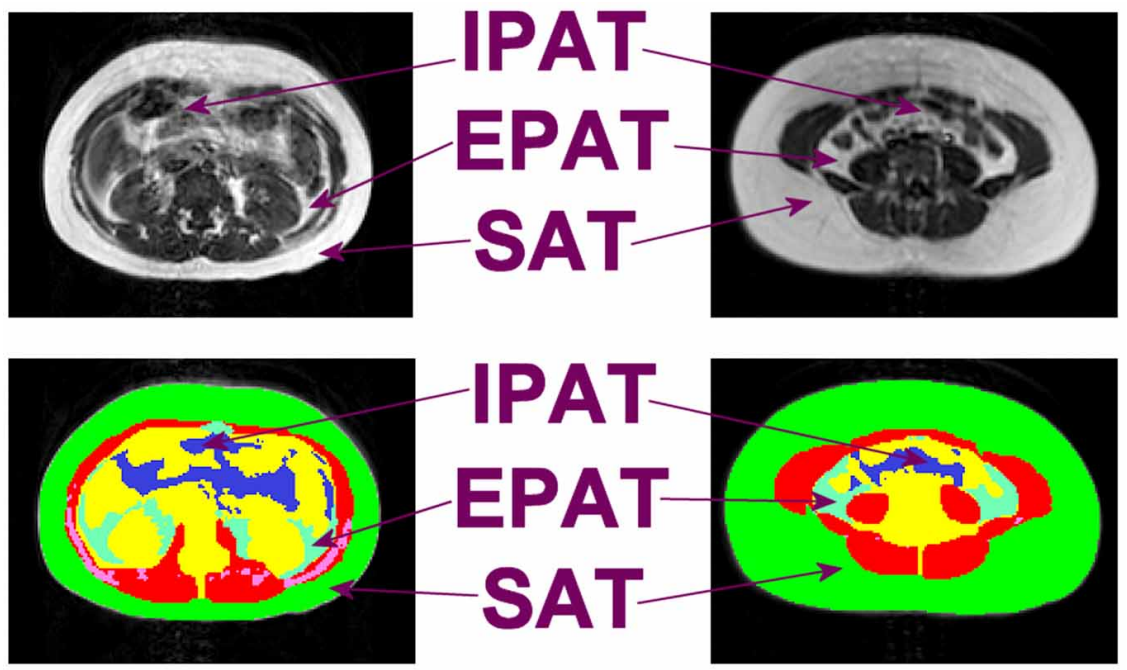

Fig. (2). The image clearly shows that intraperitoneal adipose tissue (IPAT) and extraperitoneal adipose tissue (EPAT) are separated by organs and muscles in a 14 year old girl with a relatively large amount of VAT volume (i.e. 1.6 L with 0.8 L or IPAT and 0.8 L of EPAT) comparing to an average of $0.6 \mathrm{~L}$ in girls [74].

axial photographs of a middle aged man and woman [76]. This digital image database allows 3-dimensional reconstruction of IPAT and EPAT as well as their sub-components. The analyst can gain detailed anatomic knowledge at different anatomic locations. Although variation exists among individuals, the continuation of IPAT and EPAT depots in consecutive images can serve as valuable references for segmenting IPAT and EPAT components. Even if arbitrary separation is still necessary in a small percentage of subjects at certain anatomic locations, the overall accuracy in quantifying IPAT and EPAT in children should still be much higher than that of adults.

Due to the limited availability of MRI and radiation of $\mathrm{CT}$, indirect measurements of VAT such as ultrasound, Dual-energy X-ray-absorptiometry (DXA), and anthropometry are sometimes adopted for certain studies. However, DXA cannot separate SAT from VAT. Ultrasound has been used to measure the thickness of VAT, defined as the distance between the recto-abdominis muscle and the aorta [77] or the vertebral bodies [78]. Both the semi-quantitative non-volumetric nature of ultrasound and the inter-technician variability limit the application of ultrasound methods in measuring VAT. Waist circumference measurements reflect both SAT and VAT compartments as well as lean tissue in the abdomen. Although waist circumference is a good surrogate for VAT in large scale epidemiological studies [79-80], it does not provide an accurate estimate of VAT in studies of small sample size.

\section{IMPORTANCE OF INVESTIGATING IPAT IN CHILDREN}

Due to the lack of a long term weight loss or maintenance strategy that is easy to implement in adults [81, 82], preventing childhood obesity is an important strategy for fighting the obesity epidemic. However, existing information is fragmentary, leaving important gaps in our understanding of the relationship between adipose tissue distribution in the early years of life and obesity related morbidities later in adulthood.
Obesity in childhood is not only related to childhood health risks [83] such as metabolic syndrome [84] and insulin resistance [85], but also to adult obesity [86, 87] and associated morbidity and mortality [88, 89]. As growing evidence suggests that VAT conveys higher health risk than SAT, it is important to accurately quantify VAT and its subdepots in order to examine whether a connection exists between risk factors present early in life and the incidence of obesity in adulthood. Accurate measurement of the subcomponents of VAT in children is also important for phenotyping, which is a requisite for gene discovery, the evaluation of pharmacological effects in vivo, and the association of subject characteristics to health status and outcome.

Although the relationship between VAT and obesity related health risks has been relatively well established in adults $[63,66,90-96]$, the role of VAT in the health risks for children remains controversial with inconsistent findings in previous studies [97-107]. A relationship between VAT and insulin sensitivity has been observed in obese adolescents $[99,103]$ but not in nonobese adolescents, young children $[99,104]$ or children with a relatively wide range of adiposity [100]. In a sample of prepubertal children ranging from lean to overweight, VAT was found to bear health risks similar to that of total body fat in a cross-sectional sample during the early recruitment period [100]. However, when the study sample reached a larger size, total body fat appeared to have the predominant effect on fasting insulin levels [100]. The longitudinal follow up of this sample showed that abdominal SAT may be more predictive of the rate of fasting insulin change than VAT [97, 101]. It has been suggested that the associations between VAT and health risks develop with age, sexual maturation, or establishment of disease [97].

Most investigations of VAT in children were based on a single image slice or a few aggregated slices near the L4-L5 level, which has proven not to be the best location for representing VAT volume in adults and children $[33,61,62$, 74]. Children have much smaller amounts of VAT than adults and thus a single slice at the L4-L5 level may be even 
less adequate to quantify VAT in children. Furthermore, while subcomponents of VAT (i.e., omental and mesenteric adipose tissue) may be closely related to health risks in adults, adolescents, and animals [8, 27, 108], there are no reports on the relationship between health risks and subcomponents of VAT in young children.

Using CT and MRI methods, it has been found that African American children have less VAT than Caucasian children [97, 104], but are more insulin resistant than their Caucasian counterparts after adjustment of total fat [97]. These observations confirm that ethnic differences in VAT amount exist in childhood. Interestingly, sex differences in VAT were not observed in childhood [74], even though sex differences in VAT have long been noticed in adulthood. There are no studies that examine whether ethnic or sex differences have an effect on IPAT or EPAT in children.

A unique feature of childhood is that almost all tissue compartments are growing. In a five year follow up study of children (ages 4.6 to 12.1 years at baseline), VAT exhibited significant growth [109]. However, Brambilla et al. found that during puberty there is a tendency for VAT to decrease in normal weight children and remain stable in obese children $[110,111]$. Since puberty may have an independent effect on adipose tissue distribution [112, 113] and Brambilla et al.'s studies only included peri-pubertal children, it is possible that puberty contributes to the inconsistencies across these studies. Puberty may also influence the manner in which changes in adipose tissue distribution occur between lean and obese children. Some studies have suggested that adipose tissue deposition before puberty is more likely to be related to insulin resistance than adipose tissue deposition during or after puberty [114]. Further investigation is needed to clarify the relationship between growth, puberty, obesity and health risks. Using CT methods, Goran et al. found that the rate of change in VAT was similar among children remaining prepubertal compared to those who entered puberty during two years of follow up. However, VAT did not change significantly in the remaining group of four children who were more advanced in pubertal status during two years of follow up [115]. These results imply that not just puberty, but also pubertal stage, should be considered when studying growth and adipose tissue distribution.

As we have mentioned earlier, there are very few studies that examine the potential health benefits of omentectomy. To our knowledge there are no omentectomy studies in children. The DAIR surgical procedure, which includes omentectomy, has been performed on at least one 14 year old child, but there is a lack of clinical trials of adequate sample size in adolescents [116]. The role of omentum in confining inflammation should also be considered when evaluating the potential benefits of omentectomy.

\section{FUTURE DIRECTIONS}

With recent advances in MRI technology and the experience gained in VAT MRI analysis, higher resolution fast scanning sequences can make the development of IPAT analysis protocols possible. Recent advances in the Periodically Rotated Overlapping Parallel Lines with Enhanced Reconstruction (PROPELLER) data acquisition showed that this technique reduces motion artifacts in pediatric brain scans [117-119] as well as breathing artifacts [120]. This technology advance, along with other fast imaging choices, provide potential solutions to the motion and breathing artifacts that have been considered problematic for pediatric MRI acquisition [121].

Future studies using advanced MRI protocols are needed to clarify the relationships between VAT partitioning, growth, puberty and obesity related health risks across different stages of childhood. Whether there are metabolic differences among the sub-depots of IPAT or EPAT may also be investigated in future studies. Clinical trials in children and adolescents are also needed to evaluate whether there are additional health benefits in regimes that target VAT or IPAT loss compared to overall weight reduction.

\section{CONCLUSION}

More knowledge about adipose tissue distribution and health risks in children is needed as part of our effort to understand and manage obese patients. Children's VAT partitioning is different from that of adults. Advances in MRI have made it possible for future studies to investigate subdepots of VAT including IPAT and EPAT. Although adipose tissue sampling in the omental and mesenteric adipose tissue compartments has greatly improved our understanding of the mechanisms at the cellular and molecular levels, biopsy of these adipose tissue depots is likely to be limited to morbidly obese subjects who undergo bariatric surgery. Imaging methods will need to fill in gaps when studying IPAT and its sub-depots in non-obese subjects or subjects in the very early stages of obesity. Accurate measurement of the sub-depots of VAT in children is important for phenotyping, which is a requisite for gene discovery and the evaluation of childhood obesity intervention methods. It is important to understand the early development of IPAT and its relationship to growth in order to construct childhood obesity prevention strategies. Future studies are also needed to establish whether weight loss interventions that target the reduction of VAT subdepots, such as omentectomy, are beneficial and practical in obese children.

\section{FINANCIAL SUPPORT}

Supported by National Institutes of Health Grant R21073720

\section{REFERENCES}

[1] Gortmaker SL, Dietz WH, Jr, Sobol AM, Wehler CA. Increasing pediatric obesity in the United States. Am J Dis Child 1987; 141: 535-40.

[2] Troiano RP, Flegal KM, Kuczmarski RJ, Campbell SM, Johnson CL. Overweight prevalence and trends for children and adolescents. The National Health and Nutrition Examination Surveys, 1963 to 1991. Arch Pediatr Adolesc Med 1995; 149: 1085-91.

[3] Rocchini AP. Childhood obesity and a diabetes epidemic. N Engl J Med 2002; 346: 854-5

[4] Strauss RS, Pollack HA. Epidemic increase in childhood overweight, 1986-1998. JAMA 2001; 286: 2845-8.

[5] Shen W, Wang ZM, Punyanita M, et al. Adipose tissue quantification by imaging methods: a proposed classification. Obes Res 2003; 11: 5-16. 
[6] Yang YK, Chen M, Clements RH, Abrams GA, Aprahamian CJ, Harmon CM. Human mesenteric adipose tissue plays unique role versus subcutaneous and omental fat in obesity related diabetes. Cell Physiol Biochem 2008; 22: 531-8.

[7] Bjorntorp P. Regional patterns of fat distribution. Ann Intern Med 1985; 103: 994-5.

[8] Björntorp P. "Portal" adipose tissue as a generator of risk factors for cardiovascular disease and diabetes. Arteriosclerosis 1990; 10: 493-6.

[9] Abate N, Burns D, Peshock RM, Garg A, Grundy SM. Estimation of adipose tissue mass by magnetic resonance imaging: validation against dissection in human cadavers. J Lipid Res 1994; 35: 14906.

[10] Björntorp P. Classification of obese patients and complications related to the distribution of surplus fat. Nutrition 1990; 6: 131-7.

[11] Abate N, Garg A, Peshock RM, Stray-Gundersen J, Adams-Huet B, Grundy SM. Relationship of generalized and regional adiposity to insulin sensitivity in men with NIDDM. Diabetes 1996; 45: 168493.

[12] Tulloch-Reid MK, Hanson RL, Sebring NG, et al. Both subcutaneous and visceral adipose tissue correlate highly with insulin resistance in african americans. Obes Res 2004; 12: 1352-9.

[13] Seidell JC, Bouchard C. Visceral fat in relation to health: is it a major culprit or simply an innocent bystander? Int J Obes Relat Metab Disord 1997; 21: 626-31.

[14] Faria AN, Ribeiro Filho FF, Gouveia Ferreira SR, Zanella MT. Impact of visceral fat on blood pressure and insulin sensitivity in hypertensive obese women. Obes Res 2002;10: 1203-6.

[15] Phillips GB, Jing T, Heymsfield SB. Relationships in men of sex hormones, insulin, adiposity, and risk factors for myocardial infarction. Metabolism 2003; 52: 784-90.

[16] Executive Summary of The Third Report of The National Cholesterol Education Program (NCEP) Expert Panel on Detection, Evaluation, And Treatment of High Blood Cholesterol In Adults (Adult Treatment Panel III). JAMA 2001; 285: 2486-97.

[17] Lambert DM, Marceau S, Forse RA. Intra-abdominal pressure in the morbidly obese. Obes Surg 2005; 15: 1225-32.

[18] Chung SJ, Kim D, Park MJ, et al. Metabolic syndrome and visceral obesity as risk factors for reflux oesophagitis: a cross-sectional case-control study of 7078 Koreans undergoing health check-ups. Gut. 2008; 57: 1360-5.

[19] Tsai CJ, Leitzmann MF, Willett WC, Giovannucci EL. Central adiposity, regional fat distribution, and the risk of cholecystectomy in women. Gut 2006; 55: 708-14.

[20] Wang SN, Yeh YT, Wang ST, et al. Visfatin--a proinflammatory adipokine-in gallstone disease. Am J Surg 2010; 199: 459-65.

[21] Schafer H, Pauleit D, Sudhop T, Gouni-Berthold I, Ewig S, Berthold HK. Body fat distribution, serum leptin, and cardiovascular risk factors in men with obstructive sleep apnea. Chest 2002; 122: 829-39.

[22] Yamamoto Y, Fujiuchi S, Hiramatsu M, et al. Resistin is closely related to systemic inflammation in obstructive sleep apnea. Respiration 2008; 76: 377-85.

[23] Razay G, Vreugdenhil A, Wilcock G. Obesity, abdominal obesity and Alzheimer disease. Dement Geriatr Cogn Disord 2006; 22: 173-6.

[24] Whitmer RA, Gustafson DR, Barrett-Connor E, Haan MN, Gunderson EP, Yaffe K. Central obesity and increased risk of dementia more than three decades later. Neurology 2008; 71: 105764.

[25] Lear SA, Humphries KH, Kohli S, Frohlich JJ, Birmingham CL, Mancini GB. Visceral adipose tissue, a potential risk factor for carotid atherosclerosis: results of the Multicultural Community Health Assessment Trial (M-CHAT). Stroke 2007; 38: 2422-9.

[26] Howard JM, Pidgeon GP, Lysaght J, Ennis D, Reynolds JV. Obesity and the Metabolic Syndrome As a Risk Factor in GI Cancers: Colorectal and Esophageal Tumour Cell Survival Is Regulated By Visceral Adipose Tissue. Gastroenterology 2008; 134: A-26.

[27] Thorne A, Lonnqvist F, Apelman J, Hellers G, Arner P. A pilot study of long-term effects of a novel obesity treatment: omentectomy in connection with adjustable gastric banding. Int $\mathbf{J}$ Obes Relat Metab Disord 2002; 26: 193-9.

[28] Maffei M, Halaas J, Ravussin E, et al. Leptin levels in human and rodent: measurement of plasma leptin and ob RNA in obese and weight-reduced subjects. Nat Med 1995; 1: 1155-61.
[29] Scherer PE, Williams S, Fogliano M, Baldini G, Lodish HF. A novel serum protein similar to $\mathrm{Clq}$, produced exclusively in adipocytes. J Biol Chem 1995; 270: 26746-9.

[30] Kanaya AM, Harris T, Goodpaster BH, Tylavsky F, Cummings SR. Adipocytokines attenuate the association between visceral adiposity and diabetes in older adults. Diabetes Care 2004; 27 : 1375-80.

[31] Yatagai T, Nagasaka S, Taniguchi A, et al. Hypoadiponectinemia is associated with visceral fat accumulation and insulin resistance in Japanese men with type 2 diabetes mellitus. Metabolism 2003; 52: $1274-8$.

[32] Despres JP, Lemieux I. Abdominal obesity and metabolic syndrome. Nature 2006; 444: 881-7.

[33] Shen W, Punyanitya M, Wang Z, et al. Visceral adipose tissue: relations between single-slice areas and total volume. Am J Clin Nutr 2004; 80: 271-8.

[34] Ukkola O, Santaniemi M. Adiponectin: a link between excess adiposity and associated comorbidities? J Mol Med 2002; 80: 696702.

[35] Rasmussen MS, Lihn AS, Pedersen SB, Bruun JM, Rasmussen M, Richelsen B. Adiponectin receptors in human adipose tissue: effects of obesity, weight loss, and fat depots. Obesity (Silver Spring) 2006; 14: 28-35.

[36] Steppan CM, Bailey ST, Bhat S, et al. The hormone resistin links obesity to diabetes. Nature 2001; 409: 307-12.

[37] Moon B, Kwan JJ, Duddy N, Sweeney G, Begum N. Resistin inhibits glucose uptake in L6 cells independently of changes in insulin signaling and GLUT4 translocation. Am J Physiol Endocrinol Metab 2003; 285: E106-15.

[38] Rajala MW, Obici S, Scherer PE, Rossetti L. Adipose-derived resistin and gut-derived resistin-like molecule-beta selectively impair insulin action on glucose production. J Clin Invest 2003; 111: $225-30$.

[39] Jain SH, Massaro JM, Hoffmann U, et al. Cross-sectional associations between abdominal and thoracic adipose tissue compartments and adiponectin and resistin in the Framingham Heart Study. Diabetes Care 2009; 32: 903-8.

[40] Lemieux I, Pascot A, Prud'homme D, et al. Elevated C-reactive protein: another component of the atherothrombotic profile of abdominal obesity. Arterioscler Thromb Vasc Biol 2001; 21: 9617.

[41] Cigolini M, Targher G, Bergamo Andreis IA, Tonoli M, Agostino G, De Sandre G. Visceral fat accumulation and its relation to plasma hemostatic factors in healthy men. Arterioscler Thromb Vasc Biol 1996; 16: 368-74.

[42] Mertens I, Van Gaal LF. Visceral fat as a determinant of fibrinolysis and hemostasis. Semin Vasc Med 2005; 5: 48-55.

[43] Cigolini M, Targher G, Seidell JC, et al. Relationships of plasminogen activator inhibitor-1 to anthropometry, serum insulin, triglycerides and adipose tissue fatty acids in healthy men. Atherosclerosis 1994; 106: 139-47.

[44] Landin K, Stigendal L, Eriksson E, et al. Abdominal obesity is associated with an impaired fibrinolytic activity and elevated plasminogen activator inhibitor-1. Metabolism 1990; 39: 1044-8.

[45] Vague P, Juhan-Vague I, Chabert V, Alessi MC, Atlan C. Fat distribution and plasminogen activator inhibitor activity in nondiabetic obese women. Metabolism 1989; 38: 913-5.

[46] Miyazawa-Hoshimoto S, Takahashi K, Bujo H, Hashimoto N, Saito Y. Elevated serum vascular endothelial growth factor is associated with visceral fat accumulation in human obese subjects. Diabetologia 2003; 46: 1483-8.

[47] Maury E, Ehala-Aleksejev K, Guiot Y, Detry R, Vandenhooft A, Brichard SM. Adipokines oversecreted by omental adipose tissue in human obesity. Am J Physiol Endocrinol Metab 2007; 293: E656-65.

[48] Cancello R, Henegar C, Viguerie $\mathrm{N}$, et al. Reduction of macrophage infiltration and chemoattractant gene expression changes in white adipose tissue of morbidly obese subjects after surgery-induced weight loss. Diabetes 2005; 54: 2277-86.

[49] Nair S, Lee YH, Rousseau E, et al. Increased expression of inflammation-related genes in cultured preadipocytes/stromal vascular cells from obese compared with non-obese Pima Indians. Diabetologia 2005; 48: 1784-8.

[50] Jernas M, Palming J, Sjoholm K, et al. Separation of human adipocytes by size: hypertrophic fat cells display distinct gene expression. FASEB J 2006; 20: 1540-2. 
[51] Skurk T, Alberti-Huber C, Herder C, Hauner H. Relationship between adipocyte size and adipokine expression and secretion. $\mathrm{J}$ Clin Endocrinol Metab 2007; 92: 1023-33.

[52] Cao YL, Hu CZ, Meng X, Wang DF, Zhang J. Expression of TNFalpha protein in omental and subcutaneous adipose tissue in obesity. Diabetes Res Clin Pract 2008; 79: 214-9.

[53] Cancello R, Tordjman J, Poitou C, et al. Increased infiltration of macrophages in omental adipose tissue is associated with marked hepatic lesions in morbid human obesity. Diabetes 2006; 55: 155461 .

[54] Santoro S, Milleo FQ, Malzoni CE, et al. Enterohormonal changes after digestive adaptation: five-year results of a surgical proposal to treat obesity and associated diseases. Obes Surg 2008; 18: 17-26.

[55] Velhote MC, Damiani D, Santoro S. Bariatric surgery in pediatrics-is it time? J Pediatr Endocrinol Metab 2007; 20: 751-61.

[56] Hansen E, Hajri T, Abumrad NN. Is all fat the same? The role of fat in the pathogenesis of the metabolic syndrome and type 2 diabetes mellitus. Surgery 2006; 139: 711-6.

[57] Gabriely I, Ma XH, Yang XM, et al. Removal of visceral fat prevents insulin resistance and glucose intolerance of aging: an adipokine-mediated process? Diabetes 2002; 51: 2951-8.

[58] Barzilai N, She L, Liu BQ, et al. Surgical removal of visceral fat reverses hepatic insulin resistance. Diabetes 1999; 48: 94-8.

[59] Kim YJ, Park T. Genes are differentially expressed in the epididymal fat of rats rendered obese by a high-fat diet. Nutr Res 2008; 28: 414-22.

[60] Goran MI, Malina RM. Fat distribution during childhood and adolescence: Implications for later health outcomes. Am J Hum Biol 1999; 11: 187-8.

[61] Shen W, Punyanitya M, Chen J, et al. Visceral adipose tissue: relationships between single slice areas at different locations and obesity-related health risks. Int J Obes (Lond) 2007; 31: 763-9.

[62] Demerath EW, Shen W, Lee M, et al. Approximation of total visceral adipose tissue with a single magnetic resonance image. Am J Clin Nutr 2007; 85: 362-8

[63] Ross R, Fortier L, Hudson R. Separate associations between visceral and subcutaneous adipose tissue distribution, insulin and glucose levels in obese women. Diabetes Care 1996; 19: 1404-11.

[64] Ross R, Rissanen J, Pedwell H, Clifford J, Shragge P. Influence of diet and exercise on skeletal muscle and visceral adipose tissue in men. J Appl Physiol 1996; 81: 2445-55.

[65] Ross R, Shaw KD, Rissanen J, Martel Y, Guise Jd, Avruch L. Sex differences in lean and adipose tissue distribution by magnetic resonance imaging: anthropometric relationships. Am J Clin Nutr 1994; 59: 1277-85.

[66] Ross R, Aru J, Freeman J, Hudson R, Janssen I. Abdominal adiposity and insulin resistance in obese men. Am J Physiol Endocrinol Metab 2002; 282: E657-63.

[67] Janssen I, Ross R. Effects of sex on the change in visceral, subcutaneous adipose tissue and skeletal muscle in response to weight loss. Int J Obes Relat Metab Disord 1999; 23: 1035-46.

[68] Tai ES, Lau TN, Ho SC, Fok AC, Tan CE. Body fat distribution and cardiovascular risk in normal weight women. Associations with insulin resistance, lipids and plasma leptin. Int J Obes Relat Metab Disord 2000; 24: 751-7.

[69] van der Kooy K, Seidell JC. Techniques for the measurement of visceral fat: a practical guide. Int J Obes Relat Metab Disord 1993; 17: 187-96.

[70] Abate N, Garg A, Peshock RM, Stray-Gundersen J, Grundy SM. Relationships of generalized and regional adiposity to insulin sensitivity in men. J Clin Invest 1995; 96: 88-98.

[71] Ashwell M, McCall SA, Cole TJ, Dixon AK. Fat distribution and its metabolic complications: Interpretations. In: Norgan NG, Ed. Eruro-Nut Conference Series: Human body composition and fat distribution. The Hague: CIP gegevens Koninklijke Bibliotheek; 1987. p. 227-43

[72] Shen W, Punyanita M, Heshka S, Heymsfield SB, Eds. High resolution magnetic resonance imaging successfully separates regional abdominal adipose tissue. The North American Association for the Study of Obesity; 2003; Florida, USA.

[73] Olhager E, Thuomas KA, Wigstrom L, Forsum E. Description and evaluation of a method based on magnetic resonance imaging to estimate adipose tissue volume and total body fat in infants. Pediatr Res 1998; 44: 572-7.

[74] Shen W, Punyanitya M, Silva AM, et al. Sexual dimorphism of adipose tissue distribution across the lifespan: a cross-sectional whole-body magnetic resonance imaging study. Nutr Metab (Lond) 2009; 6: 17.

[75] Hartman GE. Acute Appendicitis. In: Behrman RE, Kliegman RM, Arvin AM, Nelson WE, Eds. Nelson Textbook of Pediatrics. Chapter 289. Philadelphia: W.B. Saunders company; 1996; pp.. 1109-11.

[76] The U.S. National Library of Medicine. Visible Human Project. Visible Human CD-ROM. Version 1.1 ed, 1995.

[77] Tarantino G, Colicchio P, Conca P, et al. Young adult obese subjects with and without insulin resistance: what is the role of chronic inflammation and how to weigh it non-invasively? J Inflamm (Lond) 2009; 6: 6.

[78] Finucane FM, Horton J, Purslow LR, et al. Randomized controlled trial of the efficacy of aerobic exercise in reducing metabolic risk in healthy older people: The hertfordshire physical activity trial. BMC Endocr Disord 2009; 9: 15.

[79] Zhu S, Heshka S, Wang Z, et al. Combination of BMI and waist circumference for identifying cardiovascular risk factors in whites. Obes Res 2004; 12: 633-45.

[80] Zhu S, Wang Z, Heshka S, Heo M, Faith MS, Heymsfield SB. Waist circumference and obesity-associated risk factors among whites in the third National Health and Nutrition Examination Survey: clinical action thresholds. Am J Clin Nutr 2002; 76: 743-9.

[81] Klem ML, Wing RR, McGuire MT, Seagle HM, Hill JO. A descriptive study of individuals successful at long-term maintenance of substantial weight loss. Am J Clin Nutr 1997; 66: 23946.

[82] Wadden TA, Vogt RA, Foster GD, Anderson DA. Exercise and the maintenance of weight loss: 1-year follow-up of a controlled clinical trial. J Consult Clin Psychol 1998; 66: 429-33.

[83] Williams DP, Going SB, Lohman TG, et al. Body fatness and risk for elevated blood pressure, total cholesterol, and serum lipoprotein ratios in children and adolescents. Am J Public Health 1992; 82: 358-63.

[84] Weiss R, Dziura J, Burgert TS, et al. Obesity and the metabolic syndrome in children and adolescents. N Engl J Med 2004; 350: 2362-74.

[85] Rosenbaum M, Nonas C, Horlick M, et al. beta-Cell function and insulin sensitivity in early adolescence: association with body fatness and family history of type 2 diabetes mellitus. J Clin Endocrinol Metab 2004; 89: 5469-76.

[86] Serdula MK, Ivery D, Coates RJ, Freedman DS, Williamson DF, Byers T. Do obese children become obese adults? A review of the literature. Prev Med 1993; 22: 167-77.

[87] Guo SS, Roche AF, Chumlea WC, Gardner JD, Siervogel RM. The predictive value of childhood body mass index values for overweight at age 35 y. Am J Clin Nutr 1994; 59: 810-9.

[88] Nieto FJ, Szklo M, Comstock GW. Childhood weight and growth rate as predictors of adult mortality. Am J Epidemiol 1992; 136: 201-13.

[89] Must A, Jacques PF, Dallal GE, Bajema CJ, Dietz WH. Long-term morbidity and mortality of overweight adolescents. A follow-up of the Harvard Growth Study of 1922 to 1935. N Engl J Med 1992; 327: $1350-5$.

[90] Ross R, Dagnone D, Jones PJ, et al. Reduction in obesity and related comorbid conditions after diet-induced weight loss or exercise-induced weight loss in men. A randomized, controlled trial. Ann Intern Med 2000; 133: 92-103.

[91] Gautier JF, Milner MR, Elam E, Chen K, Ravussin E, Pratley RE. Visceral adipose tissue is not increased in Pima Indians compared with equally obese Caucasians and is not related to insulin action or secretion. Diabetologia 1999; 42: 28-34.

[92] Goodpaster BH, Krishnaswami S, Resnick H, et al. Association between regional adipose tissue distribution and both type 2 diabetes and impaired glucose tolerance in elderly men and women. Diabetes Care 2003; 26: 372-9.

[93] Rice B, Janssen I, Hudson R, Ross R. Effects of aerobic or resistance exercise and/or diet on glucose tolerance and plasma insulin levels in obese men. Diabetes Care 1999; 22: 684-91.

[94] Rendell M, Hulthen UL, Tornquist C, Groop L, Mattiasson I. Relationship between abdominal fat compartments and glucose and lipid metabolism in early postmenopausal women. J Clin Endocrinol Metab 2001; 86: 744-9.

[95] Ross R, Freeman J, Hudson R, Janssen I. Abdominal obesity, muscle composition, and insulin resistance in premenopausal women. J Clin Endocrinol Metab 2002; 87: 5044-51. 
[96] Brochu M, Starling RD, Tchernof A, Matthews DE, Garcia-Rubi E, Poehlman ET. Visceral adipose tissue is an independent correlate of glucose disposal in older obese postmenopausal women. J Clin Endocrinol Metab 2000; 85: 2378-84.

[97] Gower BA, Nagy TR, Goran MI. Visceral fat, insulin sensitivity, and lipids in prepubertal children. Diabetes 1999; 48: 1515-21.

[98] Caprio S, Hyman LD, McCarthy S, Lange R, Bronson M, Tamborlane WV. Fat distribution and cardiovascular risk factors in obese adolescent girls: importance of the intraabdominal fat depot. Am J Clin Nutr 1996; 64: 12-7.

[99] Caprio S, Hyman LD, Limb C, et al. Central adiposity and its metabolic correlates in obese adolescent girls. Am J Physiol 1995; 269: E118-26.

[100] Goran MI, Bergman RN, Gower BA. Influence of total vs. visceral fat on insulin action and secretion in African American and white children. Obes Res 2001; 9: 423-31.

[101] Huang TT, Johnson MS, Gower BA, Goran MI. Effect of changes in fat distribution on the rates of change of insulin response in children. Obes Res 2002; 10: 978-84.

[102] Goran MI, Bergman RN, Avila Q, et al. Impaired glucose tolerance and reduced beta-cell function in overweight Latino children with a positive family history for type 2 diabetes. J Clin Endocrinol Metab 2004; 89: 207-12.

[103] Owens S, Gutin B, Barbeau P, et al. Visceral adipose tissue and markers of the insulin resistance syndrome in obese black and white teenagers. Obes Res 2000; 8: 287-93.

[104] Yanovski JA, Yanovski SZ, Filmer KM, et al. Differences in body composition of black and white girls. Am J Clin Nutr 1996; 64: 833-9.

[105] Bacha F, Saad R, Gungor N, Arslanian SA. Adiponectin in youth: relationship to visceral adiposity, insulin sensitivity, and beta-cell function. Diabetes Care 2004; 27: 547-52.

[106] Roemmich JN, Clark PA, Lusk M, et al. Pubertal alterations in growth and body composition. VI. Pubertal insulin resistance: relation to adiposity, body fat distribution and hormone release. Int J Obes Relat Metab Disord 2002; 26: 701-9.

[107] Mitchell BM, Gutin B, Kapuku G, et al. Left ventricular structure and function in obese adolescents: relations to cardiovascular fitness, percent body fat, and visceral adiposity, and effects of physical training. Pediatrics 2002; 109: E73-3.

[108] Kortelainen ML, Sarkioja T. Visceral fat and coronary pathology in male adolescents. Int J Obes Relat Metab Disord 2001; 25: 228-32.

[109] Huang TT, Johnson MS, Figueroa-Colon R, Dwyer JH, Goran MI. Growth of visceral fat, subcutaneous abdominal fat, and total body fat in children. Obes Res 2001; 9: 283-9.
[110] Brambilla P, Manzoni P, Sironi S, et al. Peripheral and abdominal adiposity in childhood obesity. Int $\mathrm{J}$ Obes Relat Metab Disord 1994; 18: 795-800.

[111] Brambilla P, Manzoni P, Agostini G, et al. Persisting obesity starting before puberty is associated with stable intraabdominal fat during adolescence. Int J Obes Relat Metab Disord 1999; 23: 299303.

[112] He Q, Horlick M, Thornton J, et al. Sex-specific fat distribution is not linear across pubertal groups in a multiethnic study. Obes Res 2004; 12: 725-33.

[113] Rogol AD. Growth, body composition and hormonal axes in children and adolescents. J Endocrinol Invest 2003; 26: 855-60.

[114] Travers SH, Jeffers BW, Eckel RH. Insulin resistance during puberty and future fat accumulation. J Clin Endocrinol Metab 2002; 87: 3814-8.

[115] Goran MI. Visceral fat in prepubertal children: Influence of obesity, anthropometry, ethnicity, gender, diet, and growth. Am J Hum Biol 1999; 11: 201-7.

[116] Santoro S, Malzoni CE, Velhote MC, et al. Digestive Adaptation with Intestinal Reserve: a neuroendocrine-based operation for morbid obesity. Obes Surg 2006; 16: 1371-9.

[117] Forbes KP, Pipe JG, Bird CR, Heiserman JE. PROPELLER MRI: clinical testing of a novel technique for quantification and compensation of head motion. J Magn Reson Imaging 2001; 14 : 215-22.

[118] Forbes KP, Pipe JG, Karis JP, Farthing V, Heiserman JE. Brain imaging in the unsedated pediatric patient: comparison of periodically rotated overlapping parallel lines with enhanced reconstruction and single-shot fast spin-echo sequences. AJNR Am J Neuroradiol 2003; 24: 794-8.

[119] Alibek S, Adamietz B, Cavallaro A, et al. Contrast-enhanced T1weighted fluid-attenuated inversion-recovery BLADE magnetic resonance imaging of the brain: an alternative to spin-echo technique for detection of brain lesions in the unsedated pediatric patient? Acad Radiol 2008; 15: 986-95.

[120] Hirokawa Y, Isoda H, Maetani YS, Arizono S, Shimada K, Togashi $\mathrm{K}$. Evaluation of motion correction effect and image quality with the periodically rotated overlapping parallel lines with enhanced reconstruction (PROPELLER) (BLADE) and parallel imaging acquisition technique in the upper abdomen. J Magn Reson Imaging 2008; 28: 957-62.

[121] Shen W, Liu H, Punyanitya M, Chen J, Heymsfield SB. Pediatric obesity phenotyping by magnetic resonance methods. Curr Opin Clin Nutr Metab Care 2005; 8: 595-601. 